\title{
Double Channel Meter Reading Scheme with Micro-power Wireless and Low Voltage Power Line Carrier
}

\author{
Li Shen ${ }^{1, a}$, Hua Tian ${ }^{2, b}$ and Guiping Deng ${ }^{3, c}$ \\ ${ }^{1}$ Power Technology Center, State Grid Hubei Electric Power Research Institute, Wuhan, \\ 430077, China \\ ${ }^{2}$ Marketing Department, State Grid Hubei Electric Power Company, Wuhan, \\ 430077, China \\ ${ }^{3}$ Power Technology Center, State Grid Hubei Electric Power Research Institute, Wuhan, \\ 430077, China \\ aemail: shenlliy8888@163.com, bemail:wuhanth@sina.com, cemail:smile1248@sohu.com
}

\begin{abstract}
Keywords: Double Channel Meter Reading; Micro-power Wireless; Low Voltage Power Line Carrier; Concentrated Meter Reading Module
\end{abstract}

\begin{abstract}
In this paper, a micro-power wireless and low voltage power line carrier double channel meter reading scheme is proposed. The two communication channels of this scheme coordinate and supply each other, which takes the full advantages of each channel. The high real communication success rate and the accuracy of this meter reading scheme provide effective technical support for the construction of high efficiency, stable and practical electricity information collection system.
\end{abstract}

\section{Introduction}

The goal of the electricity information collection system is to achieve full collection information of the power users. The intact local communication link plays a key role in the reliable operation of the whole electricity information collecting system [1] [2]. Currently, electricity information collecting system in China mainly adopts low voltage narrow-band power line carrier or micro-power wireless communication mode. This single channel communication way could not meet all kinds of application environment of meter reading. The diversity of the system applications has also put forward higher requirements to the local communication, while these higher requirements are difficult to be satisfied by the single local channel communication mode. To find the suitable communication way which can adjust for different conditions is the only way to meet the requirements of meter reading.

In this paper, the double channel meter reading scheme with micro-power wireless and low voltage power line carrier is proposed. The switch between the micro-power wireless channel and the low voltage power line carrier channel is obtained by this scheme. And it overcomes the problem of relatively low communication success rate and unreliable received data of the single channel, which provides electricity information collecting system better communication ability.

\section{Characteristics Analysis of Double Channel Meter Reading Scheme}

Smart meters installed at site are divided by transformer district. The centralized management of meter reading system is realized by district unit. Installation positions of smart meters in transformer district are fixed, which ensures the fixed physical space environment without special situations. A cluster of buildings and iron materials have great attenuation effect on the wireless signal, which will affect the signal transmission distance. These changing factors such as impedance, harmonic wave and noise in the power grid have a great influence on the stability of the power line carrier signal transmission [3] [4] [5].

The distance of the micro-power wireless communication is short but its penetrating ability is strong [6]. Besides, its communication equipment can be set up or build independently, and it 
adopts different kinds of conflict avoidance mechanisms such as Ad Hoc network, automatic frequency hopping and automatic multilevel routing and so on. It can provide fast data information communication between the electricity management system and smart meters. The micro-power wireless data transmission can avoid the effects of the changes of the power grid impedance and the power grid structure. And it is convenient to do construction implementation and daily maintenance. The most major characteristic of power line carrier meter reading is using the existing power lines for data transmission.

The double channel meter reading scheme with micro-power wireless and power line carrier adopts one of them according to the actual site environment, which guarantees the meter reading channel meets the requirements of the actual site environment. Besides, the meter reading module can get electricity from the meter without external power supply.

\section{Framework of Meter Reading Scheme with Double local Communication Channels}

As shown in Fig.1, the system includes: system master station, the remote GPRS or CDMA communication channels, concentrator, the double local communication channels of power line carrier and micro-power wireless, smart meters. The data transmission between the master station and the concentrator is based on the remote communication channel, while the data transmission between the concentrator and smart meters is through the double local communication channels.

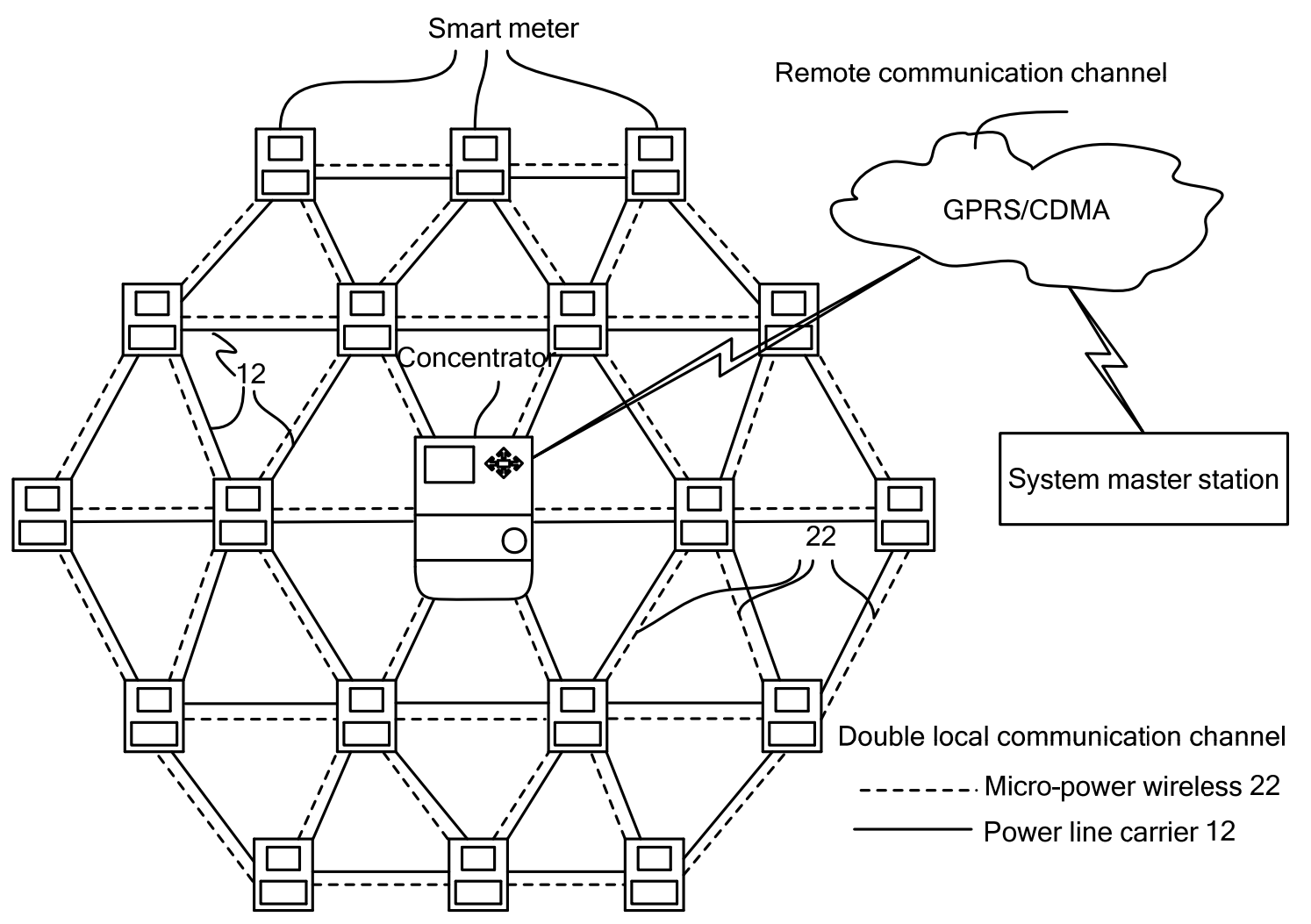

Fig. 1. Framework diagram of the electricity information collection system with double local communication channels of power line carrier and micro-power wireless

\section{Realization of the Double Channel Meter Reading Scheme}

The realization of the double channel meter reading scheme with micro-power wireless and power line carrier mainly includes two parts of the hardware implementation and communication protocol implementation.

Hardware implementation mainly includes the following four aspects.

(1) Selecting power line carrier meter reading hardware. There are mature power line carrier meter reading products in domestic. The already applied power line carrier meter reading chip and 
the receiving and transmission circuit can give hardware support for the double channel meter reading scheme with micro-power wireless and power line carrier.

(2) Module shell and interface. The double channel meter reading module with micro-power wireless and power line carrier uses a configuration similar to the power line carrier meter reading module, and the power line carrier interface and light current communication interface are reserved. The selecting and switching between the micro-power wireless channel and the power line carrier channel is realized by a micro-controller, which is connected to the light current interface of the smart meter to realize data transmission.

(3) The micro-power wireless antenna. The loop antenna is adopted for micro-power wireless antenna, and it is placed inside the meter reading module shell. The loop antenna can ensure the normal and stable sending and receiving performance for wireless meter reading part, and can also save the cost of the RF antenna.

(4) Module indicator. The communication indicator light is set for the double channel meter reading with micro-power wireless and power line carrier, which makes it easy to identify the data transceiver between two channels and it is convenient to do further maintenance and management.

On the basis of power line carrier meter reading technology and Ad Hoc network technology, a wireless channel is added in the double channel meter reading scheme with micro-power wireless and power line carrier. After the installation of double channel meter reading module in concentrator and smart meters, all network nodes did not have networking information at first. The routing unit of the concentrator automatically starts the double channel network construction tasks. According to the distribution of smart meters in the transformer district, the routing unit will establish a rapid converged network with the concentrator as the center for all smart meters in the transformer district, which will automatically select the optimal channel and path.

After the completion of the network establishment, the entire routing information needs network optimization. This part mainly takes the advantages of the centralized network. The routing can be optimized in accordance with the network structure for previous network establishment. When congestion and local failure emerge in the network, automatically adaptive listening part starts working to repair network. When the center node moved or changed in the network, the network will rebuilt automatically.

In the single local channel meter reading scheme, when doing the network repair in the wireless or power line carrier Ad Hoc network technology, the network optimization and repair can only be completed through the master node, which leads to meter reading with low real time and accuracy. The two local channels meter reading scheme proposed in this paper adopts the Ad Hoc network technology, which doesn't need to go through the master node and automatically optimizes the previous communication link. When a slave node in the operating network fails to maintain communication because of blockage or partial failure, the adjacent nodes which share the same parent and child nodes with the disabled slave node will detect and listen to the failure news immediately. Since more than one adjacent node can listen to the news, so the comprehensive communication quality considering both upward and downward data transmission is used to select the optimal adjacent node. Because each node can detect the communication quality of own down link and record the relevant parameter values, the parent node of adjacent nodes can able to know the comprehensive communication quality considering both up and down link of all those adjacent nodes. According to the comprehensive communication quality, an optical up and down communication link and the adjacent node to realize the optical link are selected to respectively replace the failed communication link and node because of congestion or partial failure, which realizes the automatic network optimization for the previous network communication link.

Double channel communication is adopted between the concentrator and smart meters with power line carrier and micro-power wireless working in parallel, which means when one channel fails, the communication will switch to another channel automatically, which realizes the higher meter reading communication success rate and accuracy. 


\section{Conclusion}

The double channel meter reading scheme proposed in this paper has run an operational test on site. Field monitoring data shows stable communication and high real-time meter reading success rate. Compared to the way of single channel meter reading, the double channel meter reading scheme not only has improved a lot on the meter reading success rate, but also greatly improves the meter reading efficiency. With the in-depth application of smart meter, the double channel meter reading scheme with micro-power wireless and power line carrier proposed in this paper has laid a good foundation for the realization of the intelligent electricity. According to application effect, the further improvement will be made for this proposed scheme to meet the needs of the electricity information collection system with increasing complexity and diversified applications.

\section{References}

[1] Baohui Lu and Yonghong Ma. Research on Communication System of Advanced Metering Infrastructure for Smart Grid and Its Data Security Measures[J]. Power System Technology. 2013:37 (8):2244-2249.

[2] Ye Yan,Yi Qian and Sharif Hamid. A Secure and Reliable In-network Collaborative Communication Scheme for Advanced Metering Infrastructure in Smart Grid. Proceedings 2011 IEEE Wireless Communications and Networking Conference [C]. 2011.

[3] Papandreou N,Antonakopoulos T.Resource allocation management for indoor power-line communications systems[J].IEEE Transactions on Power Delivery.2007:22 (2):893-903.

[4] Meng H,Guan Y L,Chen S. Modeling and analysis of noise effects on broadband power-line communications[J]. IEEE Transactions on Power Delivery.2005:20 (2):630-637.

[5] Morosi S,Marabissi D,Enrico Del Re,et al. A rate adaptive bit-loading algorithm for in-building power-line communications based on DMT-modulated systems[J]. IEEE Transactions on Power Delivery.2006:21 (4):1892-1897.

[6] Qian Jianhua, Chen Baichao. An automatic meter reading system based on wireless communication[J]. Power System Technology.2004:28 (5):73-76. 